\title{
C-Ti (Carbon-Titanium)
}

\section{H. Okamoto}

[95Alb] proposed a Ti-C phase diagram (see [950ka] lit. rev.) by thermodynamic optimization of phase boundary data obtained by [65Rud], [89Loo], and [95Alb], and thermodynamic data obtained by [95Alb]. However, [96Sei] found that the Gibbs energy description of the liquid phase used by [95Alb] is a mathematical artifact not warranted experimentally. Figure 1 shows the Ti-C phase diagram calculated by [96Sei]. The result agrees well with experimental phase boundary data reported by [53Cad], [56 Wag], [59Bic], [62Bit], [65Rud], and [89Loo]. In addition to TiC in Fig. 1, an ordered phase $\mathrm{Ti}_{2} \mathrm{C}$ may exist with a maximum transformation temperature at $\sim 1900{ }^{\circ} \mathrm{C}$ [87Mur].

\section{Cited References}

53Cad: I. Cadoff and J.P. Nielsen, Trans. Metall. Soc. AIME, 197, 248254(1953).
56Wag: F.C. Wagner, E.J. Bucur, and M.A. Steinberg, Met. Trans. ASM, 48, 742-761 (1956).

59Bic: R.L. Bickerdike and G. Hughes, J. Less-Common Met., 1, $42-49$ (1959).

62Bit: H. Bittner and H. Goretzki, Monatsh. Chem., 93, 1000-1004 (1962).

65Rud: E. Rudy, AFML-TR-65-2 Part I, Vol. IV, Air Force Materials Laboratory Research and Technology Division, Air Force Systems Command, Wright-Patterson AFB, Ohio (1963).

87Mur: J. Murray, Phase Diagrams of Binary Titanium Alloys, ASM International, Metals Park, OH, 47-51 (1987).

89Loo: F.J.J. van Loo and G.F. Bastin, Met. Trans. A, 20, 403-411 (1989).

95Alb: K. Albertsen and H.J. Schaller, Z. Metallkde., 86(5), 319-325 (1995).

950ka: H. Okamoto, J. Phase Equilibria, 16(6), 532-533(1996).

96Sei: H.J. Seifert, H.L. Lukas, and G. Petzow, J. Phase Equilibria, 17(1), 24-35(1996).

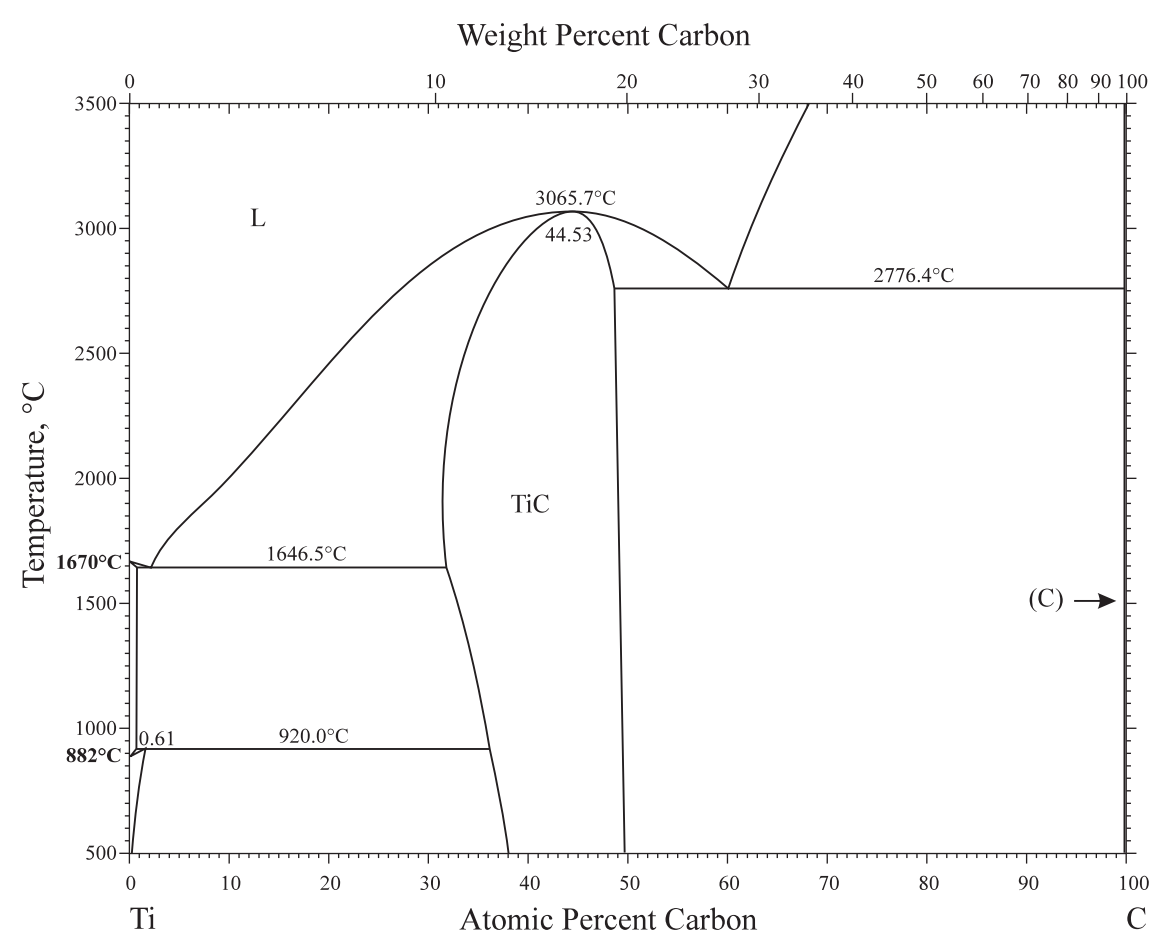

Fig. 1 The Ti-C phase diagram. 